\title{
Erratum to: Performance Analysis of Device-to-Device Communications in Cellular Networks Under Varying Load Conditions
}

\author{
Priyadarshi Ashok Dahat ${ }^{1} \cdot$ Suvra Sekhar Das $^{1}$
}

Published online: 5 June 2015

(C) Springer Science+Business Media New York 2015

\section{Erratum to: Wireless Pers Commun DOI 10.1007/s11277-015-2501-4}

The communication lines are missing in Fig. 1 in the original publication. The correct figure is shown below.

The online version of the original article can be found under doi:10.1007/s11277-015-2501-4.

Priyadarshi Ashok Dahat

priyadarshi@gssst.iitkgp.ernet.in; pashok.dahat@gmail.com

Suvra Sekhar Das

suvra@gssst.iitkgp.ernet.in

1 G. S. Sanyal School of Telecommunications, Indian Institute of Technology, Kharagpur, India 


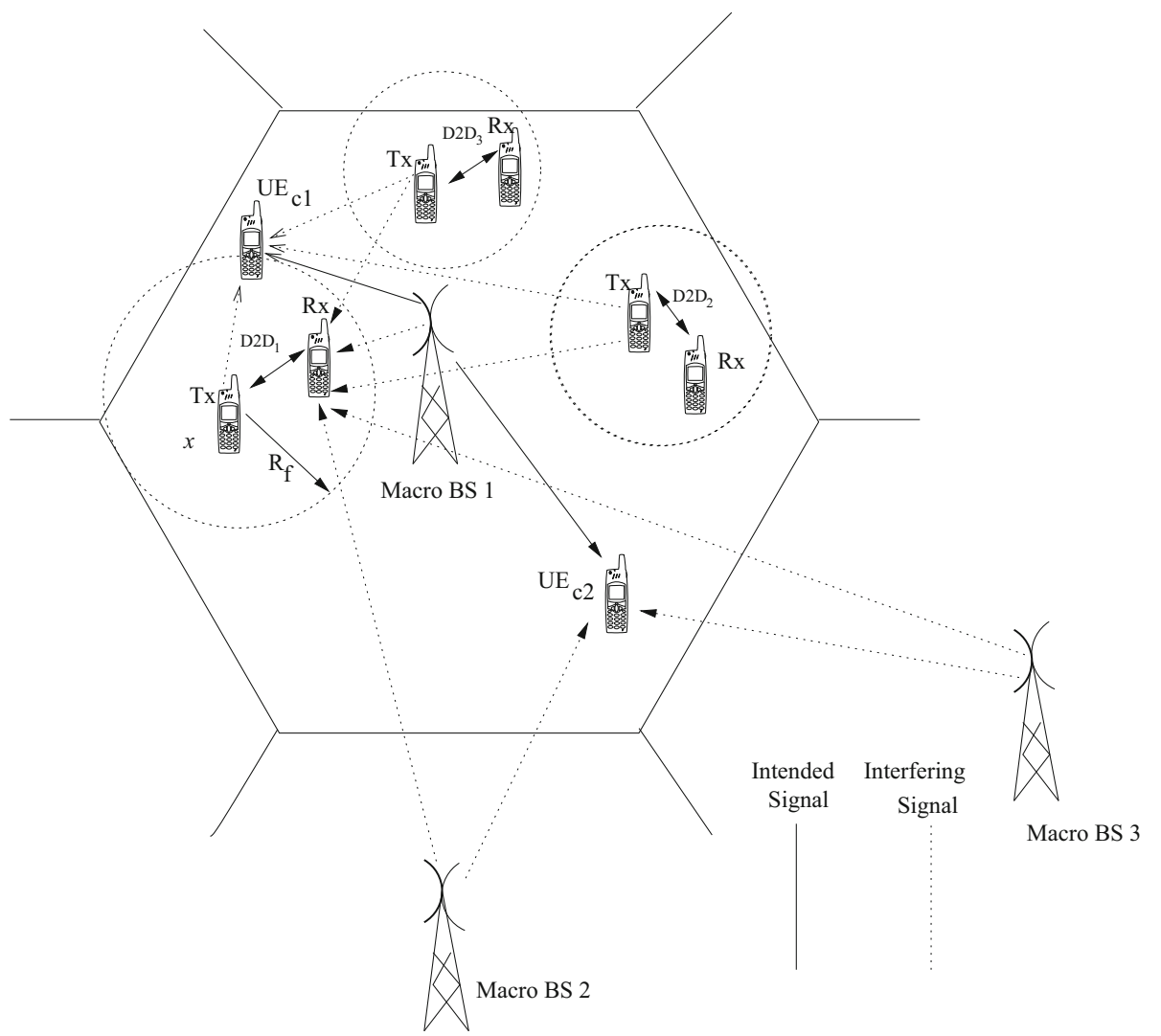

Fig. 1 System model for mixed cellular and D2D communications 